
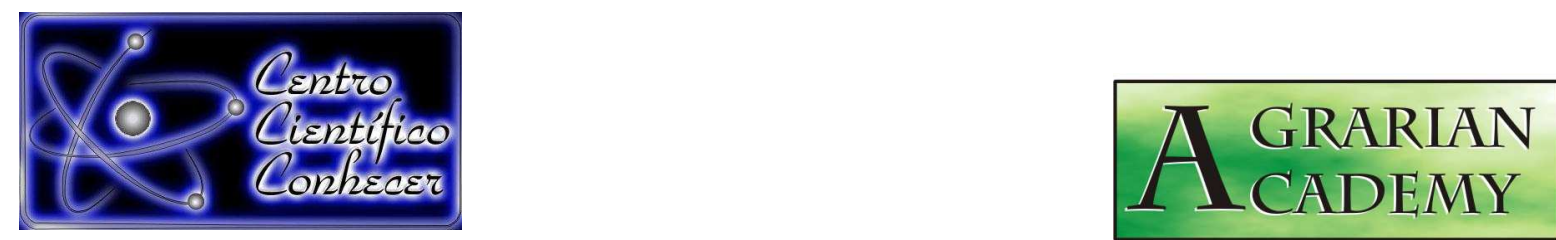

\title{
SEMENTES CRIOULAS: SUSTENTABILIDADE NO SEMIÁRIDO PARAIBANO
}

Michele da Silva Santos ${ }^{1}$, Mara Karinne Lopes Veriato Barros², Helder Morais Mendes Barros ${ }^{3}$, Karina Xavier Leite Barosi ${ }^{4}$, Luciana Rodrigues Chicó ${ }^{5}$

1 - Mestre em Eng. Agrícola, Professora, Unipampa - Universidade Federal do Pampa. Itaqui, Rio Grande do Sul. E-mail: michelef1v@hotmail.com

2 - Mestranda em Recursos Naturais pela Universidade Federal de Campina Grande, Campina Grande, Paraíba

3 - Doutor em Engenharia Agrícola. Universidade Federal de Campina Grande, Campina Grande, Paraíba.

4 - Advogada- Faculdade de Ciências Sociais Aplicadas, FACISA, Campina Grande, Paraíba.

5 - Graduada em História - Universidade Federal de Campina Grande, Campina Grande, Paraíba.

Recebido em: 15/04/2017 - Aprovado em: 22/07/2017 - Publicado em: 31/07/2017 DOI: 10.18677/Agrarian_Academy_2017a39

Na Paraíba as sementas crioulas foram batizadas por sementes da paixão, devido à sua importância reconhecida, sobretudo pelas famílias agricultoras. Essas sementes são as que melhor se adaptam a cada região onde ocorrem, visto que elas se aperfeiçoaram por meio da seleção natural, na qual os indivíduos mais vigorosos permanecem. Verificam-se que as comunidades tradicionais, com seu modo peculiar de lidar com as plantas, conseguem manter um equilíbrio com o meio ambiente. Também as sementes são produzidas de acordo com os critérios de sustentabilidade, assim pode-se asseverar a grande importância das sementes da paixão em decorrência não só do seu valor nutricional e de adaptabilidade, mas também em decorrência do valor histórico, cultural e social que elas carregam, haja vista que a capacidade de valorização e de manter através de uma tradição a passagem de sementes de dadas variedades no decorrer do tempo; bem como o conhecimento acerca de tais grãos; faz com que as comunidades não estejam submetidas às variações do mercado, nem estejam sujeitas aos grãos produzidos artificialmente que por vezes são submetidas a agrotóxicos que tanto fazem mal ao homem quanto degradam o ambiente.

PALAVRAS-CHAVE: agricultura familiar, grãos, Tradição.

\section{CRIOUL SEEDS: SUSTAINABILITY IN THE SEMIÁRID PARAIBANO}

\author{
ABSTRACT \\ In Paraíba the creole fields were baptized by seeds of passion, due to their \\ importance recognized, especially by the farming families. These seeds are the ones \\ that best adapt to each region where they occur, since they have been perfected \\ AGRARIAN ACADEMY, Centro Científico Conhecer - Goiânia, v.4, n.7; p.403 2017
}


through natural selection, in which the most vigorous individuals remain. We can see that traditional communities, with their peculiar way of dealing with plants, they can maintain a balance with the environment. Also the seeds are produced according to the criteria of sustainability, thus it is possible to assert the great importance of the seeds of the passion due not only to its nutritional value and adaptability, but also because of the historical, cultural and social value they bear, given that the ability to valorize and maintain through a tradition the passing of seeds of certain varieties over time; as well as knowledge about such grains; means that communities are not subject to market variations and are not subject to artificially produced grains which are sometimes subject to pesticides that are harmful to humans or degrade the environment.

KEYWORDS: Grains, Tradition, Family Farming

\section{INTRODUÇÃO}

Historicamente a agricultura brasileira foi marcada por diversos ciclos voltados a produção em larga escala e para exportação, tais ciclos passaram desde a economia canavieira do Brasil colônia, passaram pela produção cafeeira, de soja e de milho (PENA, 2017).

Atualmente o Brasil é um dos países que mais exportam grãos no planeta e para obter um alto nível de produtividade foi necessário buscar formas de melhorar a produção através do uso de defensivos agrícolas e dos chamados transgênicos que são grãos geneticamente modificados para atingirem determinadas características como, por exemplo, maior adaptabilidade ao clima. Entretanto esse melhoramento nem sempre significa benefícios para o equilíbrio do planeta e foi justamente a percepção do desequilíbrio ambiental que fez com que fosse desenvolvido o conceito sustentabilidade (MIKHAILOVA, 2004; CARRER et al., 2010).

Nesse sentido recorre-se a PACHECO (2002) que diz:

A agricultura convencional baseia-se em praticas tais como: cultivo intensivo do solo, monocultura, irrigação, aplicação de fertilizantes inorgânicos, controle químico de pragas e manipulação genética de plantas cultivadas. Essas práticas desconsideram a dinâmica ecológica dos agroecossistemas.

Cabe uma distinção entre o que é sustentabilidade e desenvolvimento sustentável. De acordo BUARQUE (2002), o desenvolvimento sustentável se difunde como uma proposta de desenvolvimento diferenciado, e ao mesmo tempo torna-se uma alternativa, sendo definido como o desenvolvimento que satisfaz as necessidades das gerações atuais sem comprometer as gerações futuras. Sendo assim o desenvolvimento sustentável tem grande complexidade e busca autoreprodução regulada, pois o ambiente está em constante equilíbrio dinâmico.

O conceito de desenvolvimento sustentável foi consagrado pela Conferência das Nações Unidas sobre Meio Ambiente e Desenvolvimento, a chamada Rio 92, como aquele que "atende às necessidades do presente sem comprometer a possibilidade das gerações futuras atenderem às suas próprias necessidades" (RODRIGUES, 2012).

A sustentabilidade não está atrelada a ideia de desenvolvimento, apesar de corriqueiramente seja usada como sinônimo de desenvolvimento sustentável. $\mathrm{Na}$

AGRARIAN ACADEMY, Centro Científico Conhecer - Goiânia, v.4, n.7; p.404 2017 
sustentabilidade tem-se um tripé que considera o econômico e o que é ambientalmente e socialmente justo para toda a sociedade e para os ecossistemas (OLIVEIRA et al., 2012).

Por seu turno são denominadas sementes crioulas: as variedades produzidas por agricultores familiares, quilombolas, indígenas ou assentados da reforma agrária com determinadas características reconhecidas pelas comunidades que as cultivam. Tais sementes são passadas de geração em geração sendo estas de relevante importância econômica e social, porque não dizer ambiental para as comunidades (TRINDADE, 2006).

Assim a discussão de sustentabilidade é tão relevante diante as questões que envolvem o estudo das chamadas sementes crioulas, sobretudo para as comunidades do semiárido nordestino e no caso do artigo em baila para as comunidades dessa região no Estado da Paraíba; desta forma esta pesquisa buscou identificar através de uma revisão bibliográfica os fundamentos de um desenvolvimento sustentável que vem tendo êxito através dessas sementes, refletindo sobre o resgate e à tradição propagada pelos agricultores agroecológicos no Estado da Paraíba.

\section{SEMENTES CRIOULAS E/OU SEMENTES DA PAIXÃO}

A semente, princípio da vida, constitui-se numa das mais importantes inovações surgidas durante a evolução das plantas. Carrega consigo o valor da sobrevivência, da resistência, da continuidade, da perpetuação. Resultado de um longo processo natural de seleção, reluta em crescer até que as condições ambientais Ihe sejam favoráveis (ALMEIDA \& FREIRE, 2003)

A posse e o domínio das sementes representaram a mudança do ser humano, nos seus primórdios, de coletor e caçador para agricultor sedentário. Neste processo, o ser humano foi dominando técnicas de domesticação de espécies vegetais, selecionando e criando cultivares mais adaptadas ao seu ambiente (BEVILAQUA \& ANTUNES, 2008).

A diversidade biológica na agricultura é particularmente importante em regiões sujeitas a alguns tipos de estresse ambiental. Na Paraíba, assim como em boa parte da região Nordeste, as áreas agrícolas são caracterizadas pela presença de veranicos e a ocorrência de secas que podem se prolongar por até mais de dois anos (SANTOS et al., 2012).

De acordo com ALMEIDA \& FREIRE (2003) de olhos atentos ao seu mundo, comunidades de agricultores vêm observando seu meio, a natureza, seus elementos e mecanismos; vêm assim inventando e reinventando sua realidade e construindo um repertório de conhecimentos que permite, como as sementes, germinar e frutificar. Com uma lista de critérios bastante apurada, vem separando, ao longo dos anos, aquelas variedades que são mais produtivas, que são mais aceitas e alcançam melhores preços no mercado e aquelas mais saborosas (ALMEIDA, \& CORDEIRO, 2001).

Três princípios sócios técnicos são adotados nos agroecossistemas tradicionais da região: a diversificação de cultivos intra e entre espécies, a constituição e o manejo de estoques de sementes e uma rede social de construção de saberes e intercâmbio de material genético. As práticas de manejo da produção e beneficiamento das sementes das diferentes variedades são retransmitidas através de circuitos horizontais de informação, fundados na solidariedade e nas relações de 
reciprocidade tão comuns nas comunidades rurais nordestinas. Este sistema informacional local é transmitido entre vizinhos, parentes e compadres, bem como para as gerações sucessivas (ALMEIDA \& FREIRE, 2003).

As sementes crioulas fazem parte do patrimônio de diversos povos que ao longo dos tempos vêm conservando, resgatando, selecionando e valorizando variedades e raças animais, mantendo a agrobiodiversidade adaptada a cada região (NUÑEZ \& MAIA, 2006). Na Tabela 1 a seguir informa algumas das Sementes Crioulas (da Paixão) na Paraíba

TABELA 1 - Alguns tipos de Sementes Crioulas (da paixão) na Paraíba

\begin{tabular}{lcc}
\hline Nome & Nome da variedade & Ciclo \\
\hline Fava & Cara Larga de Rama & De 111 a 120 dias \\
& Cara Larga de Moita & Menos de 90 dias \\
& Orelha de Vó Vermelha & De 90 a 100 dias \\
& Branca & Menos de 90 dias \\
\hline Feijão & Macassar sempre verde & De 61 a 70 dias \\
& Preto & De 61 a 70 dias \\
& Mulatinho & De 50 a 60 dias \\
& Carioca & De 50 a 60 dias \\
& Costela de Vaca & De 50 a 60 dias \\
& Fava & De 50 a 60 dias \\
\hline Jerimum & De leite & De 81 a 90 dias \\
& Caboclo & Menos de 70 dias \\
\hline Milho & Jabatão & De 3 a 5 meses \\
& Pontinha & De 3 a 5 meses \\
& 60 dias & De 3 a 5 meses \\
& Alho & De 3 a 5 meses \\
& Branco & De 9 a 12 meses \\
\hline Coentro & Vermelho & De 9 a 12 meses \\
\hline Quiabo & Coentro & De 41 a 50 dias \\
\hline Girassol & Flor amarela & Anual \\
\hline Gergelim & Girassol & Anual \\
& Gergelim Preto & Anual \\
\hline Sorgo & Gergelim Branco & Anual \\
& Granulado & De 6 a 8 meses \\
& Canaleiro & De 9 a 12 meses \\
\hline
\end{tabular}

Fonte: DIAS et al. (2016)

No semiárido paraibano, a agricultura familiar reconstitui seus estoques de sementes a partir da produção própria de variedades locais, conhecidas como "sementes da paixão". As sementes são assim chamadas graças ao apego e carinho que os agricultores têm por estas. A frase "Semente da Paixão" é atribuída ao agricultor Cassimiro Caetano Soares - Seu Dodô, enunciada em um encontro estadual sobre sementes realizado em 1998. Tal agricultor do Sertão paraibano disse:

"O que eu quero plantar é o milho jabatão, o feijão corujinha e a fava cara larga, e não a semente que vem de fora. Essas são minhas sementes da paixão. Cada um tem suas sementes da paixão e é nessa diversidade que nós temos que nos apoiar" (SILVA \& ALMEIDA, 2007, p. 17). 
Essas sementes recebem esse nome na Paraíba também por serem sementes resistentes, adaptadas e também pelo sentimento de guardar aquela semente deixada como herança dos antepassados, que gratuitamente fizeram um serviço ambiental para preservação e perpetuação desse patrimônio genético (SANTOS et al., 2012).

As sementes crioulas são consideradas como parte de um patrimônio genético e cultural de diversos povos tradicionais, indígenas, quilombolas e de agricultores familiares, fundamentais para a conservação in situ dos recursos e da agrobiodiversidade. As sementes são consideradas recursos básicos e relevantes para autonomia, segurança alimentar e nutricional, necessárias para permanência do homem no campo com a diversificação produtiva (ARAÚJO et al. 2013).

A Convivência com o Semiárido é possível desde que se adaptem às características da região. Um ponto essencial que se almeja é uma nova relação entre o meio ambiente e a sociedade, visto que as melhorias sociais só serão alcançadas mediante a redução das fragilidades dos ecossistemas locais. Desta forma, a coexistência com o Semiárido objetiva não só as melhorias nas condições de vida da sociedade, mas uma maior participação social através da promoção da cidadania, ações socioeconômicas adequadas, em consonância com a preservação dos recursos naturais (LIMA \& WEHRMANN, 2012).

As políticas governamentais e legislações que regulamentam o mercado de sementes no Brasil concorrem, em muito, para a intensificação da pressão negativa sobre os recursos da agrobiodiversidade. Sustentando-se num enfoque técnico que visa à artificialização das condições ambientais para que as variedades tenham alto rendimento, as políticas induzem à substituição das sementes locais por aquelas geneticamente preparadas para a resposta ao emprego intensivo de insumos agroquímicos e de estreita base genética. Assim, tanto as políticas de pesquisa agrícola quanto as de crédito, extensão rural e fomento têm exercido um papel negativo no que diz respeito à conservação do patrimônio genético responsável por melhores condições de adaptação da agricultura tradicional aos ecossistemas do semiárido paraibano. Ofertando unicamente sementes de variedades desenvolvidas por centros de pesquisa, sendo que muitos dos quais são situados em outros biomas brasileiros (ALMEIDA \& FREIRE, 2003).

Com base em diversas histórias que uma centena de agricultores, portadores de experiências, se tornaram protagonistas de um processo que tanto qualificou os bancos de sementes já antigos e os estoques familiares, quanto ampliou os sistemas coletivos de garantia do abastecimento e diversidade de sementes. Foi dessa forma que os Bancos de Sementes Comunitários se multiplicaram em toda a Paraíba, formando uma rede estadual de 200 destas organizações em 60 municípios do Estado. Através dos bancos de sementes, de 1999 a 2003, 7.000 famílias de agricultores tiveram acesso a mais de 400.000 quilos de sementes de oito espécies de cultivo e mais de 40 diferentes variedades (SILVEIRA et al., 2002 ; ALMEIDA \& FREIRE, 2003).

O que se tem buscado é um reforço às estratégias já existentes de conservação e desenvolvimento dos recursos genéticos locais. Portanto, aliados ao processo de criação e ampliação dos bancos, foram desenvolvidos e fortalecidos mecanismos de intercâmbio, avaliação e resgate de variedades locais, armazenamento de sementes e gestão de estoques. O conjunto dessas ações forma 
um sistema de seguridade de sementes. Foram produzidas: cartilhas, calendário, mapas da diversidade de cada município e informativos com experiências de sucesso. Este material tem sido amplamente divulgado em diferentes eventos no Estado. Muitos agricultores e agricultoras têm apresentado suas experiências nas áreas de seleção, armazenamento, tratamento e secagem de sementes. Tudo com apoio desse material didático e dentro do contexto da cultura local, onde há grande expressão artística de teatro, música e poesia, conjugado com muita fé (ALMEIDA \& FREIRE, 2003).

É nesse universo que as variedades locais têm sido chamadas de sementes da paixão, em uma referência ao que é desejado e desenvolvido em harmonia com o ambiente e a cultura da região. Do ponto de vista técnico, o programa de formação busca aportar elementos que conduzam à reflexão e à melhoria das práticas de produção, seleção, conservação, tratamento, armazenamento de sementes. Trabalha também com conteúdos metodológicos para a ação educadora, buscando reforçar a identidade político-cultural dos agricultores, através do seu universo de concepções da vida e do mundo. O sistema de seguridade de sementes que os bancos de sementes contêm significou uma inovação social que fortaleceu e dinamizou as organizações dos agricultores, que garantiu o acesso às sementes de boa qualidade e adaptadas, que aumentou a autonomia das famílias em relação a sementes, que melhorou o desempenho econômico das lavouras e, finalmente, que diversificou as opções de variedades para as famílias de agricultores (ALMEIDA \& FREIRE, 2003).

Com a dinamização da rede estadual de bancos de sementes voltada ao intercâmbio técnico e metodológico e para a articulação política foi possível criar um ambiente político-organizativo de dimensão estadual, que permitiu a formulação e a negociação de propostas alternativas às políticas oficiais de sementes do Estado da Paraíba. Em 2002, a partir da capacidade e da força política dos agricultores de formularem e implantarem uma política pública, que a Articulação do Semiárido Paraibano conseguiu que o Governo do Estado da Paraíba repassasse recursos para que cada Banco de Sementes Comunitário comprasse as sementes de variedades locais em cada região (ALMEIDA \& FREIRE, 2003).

Essa vitória deu um novo ânimo aos agricultores, na proposta de resgate e valorização das variedades locais, porque possibilitou a recomposição dos estoques dos bancos, mantendo a diversificação. E, por outro lado, porque foi um reconhecimento do esforço dos agricultores de preservarem a biodiversidade, abrindo um precedente legal nacional, quando sementes de variedades locais foram compradas com recursos governamentais e inseridas em um programa de governo (ALMEIDA \& FREIRE, 2003).

Nesses bancos, toda a riqueza está armazenada em silos, garrafas pets ou em latões, sob a benção dos santos prediletos. As sementes da paixão são símbolos da vida em abundância, heranças deixadas pelos antepassados, cuidadas na atividade para que as futuras gerações continuem tendo acesso a esse importante bem (ALMEIDA \& FREIRE, 2003). 


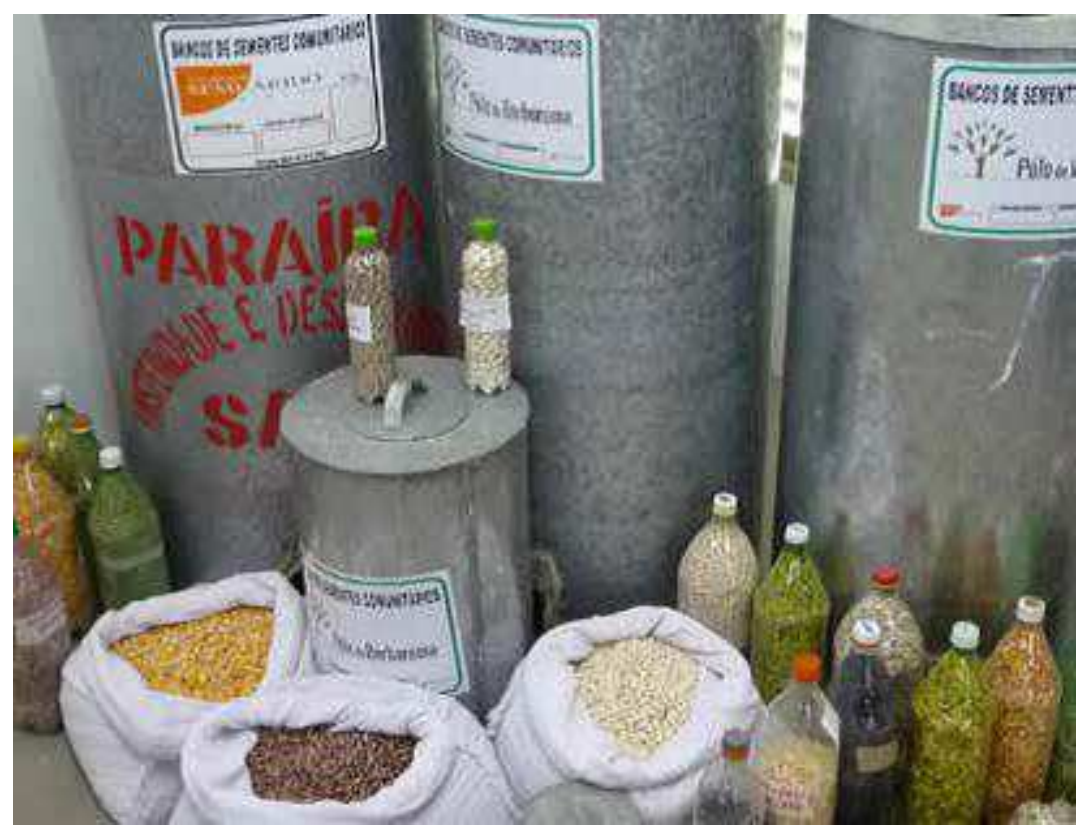

FIGURA 1 - Tipos de Armazenamento das Sementes da Paixão Fonte: LONDRES, (2014)

\section{CONDIÇÕES CLIMÁTICAS E GEOLÓGICAS DO SEMIÁRIDO}

A Região Semiárida brasileira foi delimitada com base na isoieta de $800 \mathrm{~mm}$, no Índice de Aridez de Thorntwaite de 1941 (municípios com índice de até 0,50) e no Risco de Seca (superior a 60\%). Como reflexo das condições climáticas dominantes de semiaridez, a hidrografia é pobre, em seus amplos aspectos. As condições hídricas são insuficientes para sustentar rios caudalosos que se mantenham perenes nos longos períodos de ausência de precipitações. Constitui-se exceção o rio São Francisco (IBGE, 2017).

De acordo com o IBGE (2017) o cadastro dos municípios brasileiros localizados na Região Semiárida do país, possui uma extensão total de 982.563,3 $\mathrm{km}^{2}$. Dessa área, a Região Nordeste concentra em torno de 89,5\%, abrangendo a maioria dos estados nordestinos, com a exceção do Maranhão, e o Estado de Minas Gerais, situado na Região Sudeste, possui os 10,5\% restantes (103.589,96 km). 


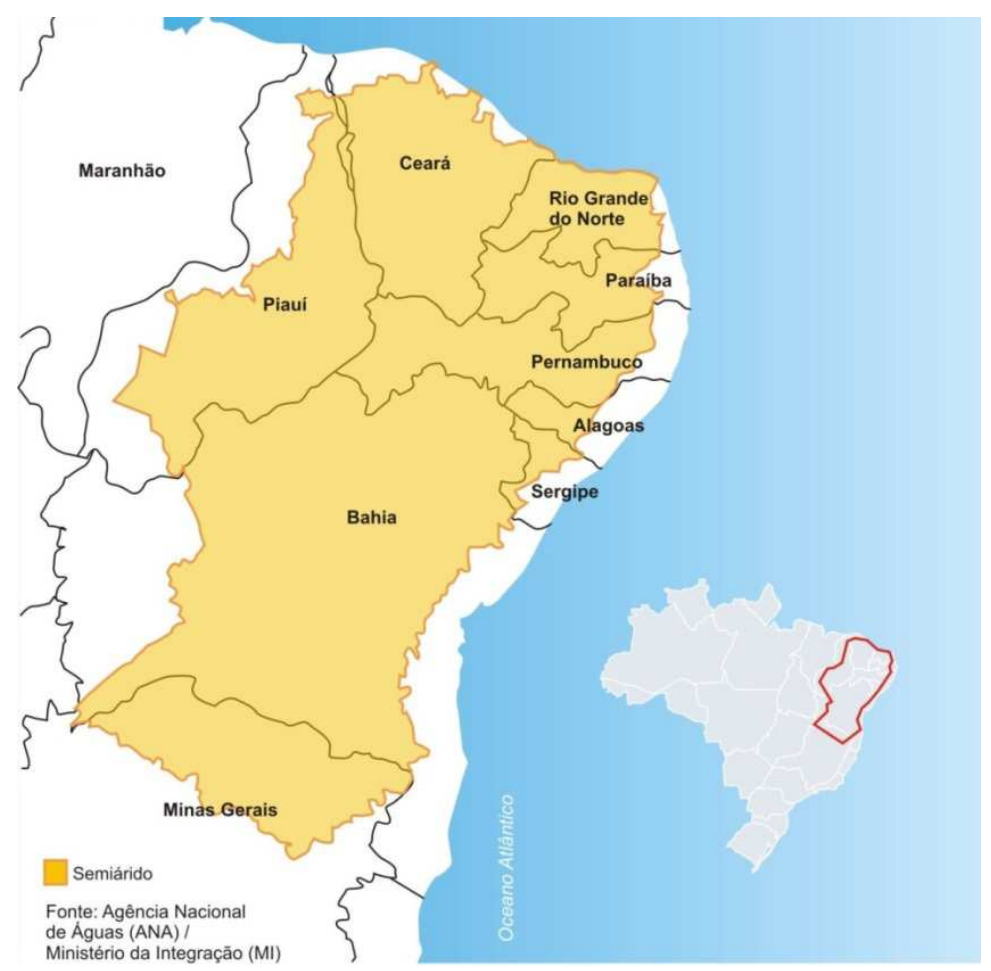

FIGURA 2 - Área do Semiárido Brasileiro Fonte: ANA, (2017).

A região sofre a influência direta de várias massas de ar (a Equatorial Atlântica, a Equatorial Continental, a Polar e as Tépidas Atlântica e Calaariana) que, de certa forma, interferem na formação do clima, mas essas massas adentram o interior do Nordeste com pouca energia, tornando extremamente variáveis não apenas os volumes das precipitações caídas, mas, principalmente, os intervalos entre as chuvas (SUASSUNA, 2002).

SUASSUNA (2017) afirma que em termos geológicos, o Nordeste é constituído por dois tipos estruturais: o embasamento cristalino, representado por $70 \%$ da região semiárida, e as bacias sedimentares. No embasamento cristalino, os solos geralmente são rasos (cerca de 0,60 m), apresentando baixa capacidade de infiltração, alto escorrimento superficial e reduzida drenagem natural.

Nas bacias sedimentares, os solos geralmente são profundos (superiores a dois metros, podendo ultrapassar seis metros), com alta capacidade de infiltração, baixo escorrimento superficial e boa drenagem natural. Apesar de serem possuidoras de um significativo volume de água no subsolo, as bacias sedimentares estão localizadas de forma esparsa no Nordeste (verdadeiras ilhas distribuídas desordenadamente no litoral e no interior da região), com volumes distribuídos de forma desigual (SUASSUNA, 2017).

\section{SEMENTES CRIOULAS (DA PAIXÃO) E A LEGISLAÇÃO}

No Brasil, esse movimento se concretiza com a Lei Federal n. 9.456 de 25/04/1997 - Lei de Proteção de Cultivares, que impedia a comercialização de sementes locais, também conhecidas como sementes crioulas, por parte dos agricultores de baixa renda (BRASIL 1997). 
Em novembro de 2001, foi adotado o Tratado Internacional sobre Recursos Fitogenéticos para a Alimentação e a Agricultura (TIRFAA), entrando em vigor efetivamente no Brasil em 2002, ratificado em 2006. Este tratado reconhece os homens do campo e os povos indígenas como sujeitos de inovação e melhoramento genético dos recursos biológicos. Suas práticas tradicionais e modos de vida conformam a base dos direitos dos agricultores e das populações locais e indígenas (ZANONI \& FERMENT, 2011).

$\mathrm{Na}$ Paraíba, antes da liberação dos agricultores para produzir e comercializar sementes, estes, de certo modo, estavam subordinados às políticas de distribuição de sementes, geneticamente tratadas, pouco adaptadas às práticas de cultivo dos agricultores, por serem dependentes de insumos químicos. A partir da nova Lei de Sementes e Mudas, de 05 de agosto de 2003, os agricultores puderam produzir, estocar, trocar e vender entre si as sementes crioulas (PAULINO \& GOMES, 2015).

No entanto, foi em 2003 que se estabeleceu a nova Lei de Sementes e Mudas, a Lei n. 10.711/03, que permitiu aos agricultores produzirem, trocarem ou venderem sementes e mudas entre si, sem precisarem aderir ao Registro Nacional de Sementes (Renasem) e ao Registro Nacional de Cultivares (RNC), responsáveis pela fiscalização destas trocas mercantis de sementes e mudas. Essa recente brecha aberta na legislação, em 2003, foi um dos fatores que reforçaram as tentativas de legitimação das sementes crioulas por parte dos cientistas e dos agricultores ecológicos (PAULINO \& GOMES, 2015).

\section{A CONSERVAÇÃO DAS SEMENTES CRIOULAS NA PARAÍBA}

As famílias do semiárido vêm preservando as sementes crioulas ao manterem banco de sementes há várias gerações, ou seja, ao passarem as sementes de pai para filho ano após ano o patrimônio advindo da agricultura local foi preservado, podendo estar disponível hoje. No entanto a preocupação com a conservação dos grãos se intensificou a partir das décadas 70 e 80 quando foram criados bancos de sementes comunitários. De acordo com a Fundação Joaquim Nabuco o semiárido paraibano abrange 170 (cento e setenta) municípios (FUNDAÇÃO JOAQUIM NABUCO, 2017).

QUADRO 1 - Lista dos 170 Municípios do Semiárido paraibano

$\begin{array}{ccc}\text { Água Branca } & \text { Esperança } & \text { Remigio } \\ \text { Aguiar } & \text { Fagundes } & \text { Riachão } \\ \text { Alcantil } & \text { Frei Martinho } & \text { Riachão do Bacamarte } \\ \text { Algodão de Jandaira } & \text { Gado Bravo } & \text { Riacho de Santo Antônio } \\ \text { Amparo } & \text { Gurjão } & \text { Riacho dos Cavalos } \\ \text { Aparecida } & \text { Ibiara } & \text { Salgadinho } \\ \text { Arara } & \text { Igaracy } & \text { Salgado de São Felix } \\ \text { Araruna } & \text { Imaculada } & \text { Santa Cecilia } \\ \text { Areia de Baraunas } & \text { Inga } & \text { Santa Cruz } \\ \text { Areial } & \text { Itabaiana } & \text { Santa Helena } \\ \text { Aroeiras } & \text { Itaporanga } & \text { Santa Inês } \\ \text { Assunção } & \text { Itatuba } & \text { Santa Luzia } \\ \text { Bananeiras } & \text { Jerico } & \text { Santa Teresinha } \\ \text { Barauna } & \text { Juazeirinho } & \text { Santana de Mangueira }\end{array}$

AGRARIAN ACADEMY, Centro Científico Conhecer - Goiânia, v.4, n.7; p.411 2017 


\begin{tabular}{|c|c|c|}
\hline Barra de Santa Rosa & Junco do Serido & Santana dos Garrotes \\
\hline Barra de Santana & Juru & Santarem Santo Andre \\
\hline Barra de São Miguel & Lagoa & São Bentinho (São Bento de Pombal) \\
\hline Belem do Brejo do Cruz & Lagoa Seca & São Bento \\
\hline Bernardinho & Lastro & São Domingos de Pombal \\
\hline Batista & Livramento & São Domingos do Cariri \\
\hline Boa Ventura & Logradouro & São Francisco \\
\hline Boa Vista & Mae d'Água & São João do Cariri \\
\hline Bom Jesus & Malta & São João do Rio de Peixe ** \\
\hline Bom Sucesso & Maneira & São João do Tigre \\
\hline Bonito de Santa Fe & Marizopolis & São José da Lagoa Tapada ** \\
\hline Boqueirao & Massaranduba & São José de Caiana \\
\hline Brejo do Cruz & Mato Grosso & São José de Espinharas \\
\hline Brejo dos Santos & Matureia & São José de Piranhas \\
\hline Cabeceiras & Mogeiro & São José de Princesa \\
\hline Cachoeira dos Indios & Montadas & São José de Bonfim \\
\hline Cacimba de areia & Monte Horebe & São José do Brejo da Cruz \\
\hline Cacimba de Dentro & Monteiro & São José do Sabugi \\
\hline Cacimbas & Natuba & São José dos Carneiros \\
\hline Caicara & Nazarezinho & São Mamede \\
\hline Cajazeiras & Nova Floresta & São Sebastião de Lagoa de Roca \\
\hline Cajazeirinhas & Nova Olinda & São Sebastião do Umbuzeiro \\
\hline Camalau & Nova Palmeira & Serido \\
\hline Campina Grande & Olho d'Água & Serra Branca \\
\hline Campo de Santana( Tacima) & Olivedos & Serra Grande \\
\hline Caraubas & Ouro Velhos & Solanea \\
\hline Carrapateira & Parari & Soladade \\
\hline Casserengue & Passagem & Sossego \\
\hline Catingueira & Patos & Sousa \\
\hline Catole do Rocha & Paulista & Sume \\
\hline Caturite & Pedra Branca & Taperoa \\
\hline Conceição & Pedra Lavrada & Tavares \\
\hline Condado & Pianco & Teixeira \\
\hline Congo & Picui & Tenorio \\
\hline Coremas & Pocinhos & Triunfo \\
\hline Coxixola & Poço Dantas & Uirauna \\
\hline Cubati & Poço de José de Moura & Umbuzeiro \\
\hline Cuite & Pombal & Varzea \\
\hline Curral Velho & Prata & Vieirópolis \\
\hline Damião & Princesa Isabel & Vista Serrana \\
\hline Desterro & Puxinana & Zabele \\
\hline Diamante & Queimadas & \\
\hline $\begin{array}{c}\text { Dona Inês } \\
\text { Emas }\end{array}$ & Quixaba & \\
\hline
\end{tabular}

Fonte: Fundação Joaquim Nabuco (2017) 
Têm bancos de sementes comunitários com mais de 30 anos. Estes foram criados no período das Comunidades Eclesiais de Base, que tiveram um papel importante no reordenamento político e social nas décadas de 70 e 80 . As comunidades eclesiais de base, fundamentadas na teoria da libertação, construíram, junto com as comunidades rurais, os bancos de sementes comunitários. E aí, na década de 90 na Paraíba, a Articulação Semiárido Paraibano, inspirada nessas iniciativas - familiares e comunitárias, procurou mobilizar e resgatar essa experiência e também ampliar a experiência (ASA BRASIL, 2017).

Por isso que falar de sementes da paixão, como são chamadas as sementes crioulas na Paraíba, é necessário entender a relação entre às sementes crioulas e as comunidades que a cultivam nesse Estado. No semiárido paraibano desde os primórdios os camponeses têm a tradição de guardar e repassar os grãos, em ciclo não só de produção, mas de vida, uma vez que tais populações tinham como base da alimentação as sementes armazenadas e portanto conservadas para o posterior plantio, sendo então não só um patrimônio alimentar material, mas também um patrimônio da cultura local (SANTOS et al., 2012).

\footnotetext{
"Tenho orgulho de dizer que sou guardião das sementes há 36 anos, pois em 1984 começaram o BSCs, sem contar o trabalho e a vida dos meus pais, e tenho o orgulho de dizer que planto a semente que meus pais e os avós plantavam. Esse conhecimento é um patrimônio. Quando acordamos estávamos perdendo essas sementes. Por causa das políticas públicas muita gente foi se entregando. Queria que meus pais ouvissem que aquilo que eles faziam no passado, hoje está bem conquistado. O ponto mais importante é a libertação, viver com o que é nosso e viver com o que nós temos. E é com a contribuição dos nossos antepassados que hoje estamos vivendo a nossa libertação". (SANTOS et al., 2012).
}

De acordo com MORAIS et al., (2014) o Coletivo Regional das Organizações da Agricultura Familiar mais conhecido como coletivo; uma articulação composta por organizações formais e informais da agricultura familiar presente em 11 municípios paraibanos nas regiões do Cariri, Curimataú e Seridó; Deu inicio em 2009 a um mapeamento dos guardiões e guardiãs das sementes crioulas, os guardiões são agricultores que exercem papel estratégico na conservação das sementes, pois além de selecionar, guardar e multiplicar as sementes, conhecem as mais adaptadas às suas localidades e repassam esses conhecimentos para as gerações seguintes.

A ASA Paraíba estima que Hoje são mais de 150 bancos de sementes comunitários no semiárido paraibano. A ASA é uma rede que defende, propaga e põe em prática, de convivência com o Semiárido, é formada por mais de três mil organizações tais como cooperativas, sindicatos rurais, associações de agricultores e ONG's; abrangendo os estados da Paraíba, Bahia, Sergipe, Alagoas, Pernambuco, Rio Grande do Norte, Ceará, Piauí, Maranhão e Minas Gerais. O surgimento da ASA está diretamente relacionado ao processo de mobilização e fortalecimento da sociedade civil no início da década de 1990. Um dos mais marcantes foi a ocupação da Superintendência de Desenvolvimento do Nordeste (Sudene), em 1993, com o objetivo de pautar a convivência com o Semiárido em contraposição à política governamental vigente na época. A missão é fortalecer a 
sociedade civil na construção de processos participativos para o desenvolvimento sustentável e a convivência com o Semiárido referenciados em valores culturais e de justiça social. E a ASA fortalece a sociedade civil mobilizando-a. Uma das estratégias que a Articulação utiliza para a mobilização social é a Comunicação Popular, assim como processos de sistematização de experiências e de intercâmbio entre as famílias agricultoras, que promovem a construção coletiva do conhecimento (ASA BRASIL, 2017).

A Rede de Sementes da ASA-PB realiza um esforço de atualização do mapa de BSCs da Paraíba, levantando informações a respeito do número de BSCs em cada município, número de Bancos Mãe e Bancos Regionais, número de famílias envolvidas nas dinâmicas dos bancos, quantidade de sementes que circulam nos bancos e as variedades que são conservadas. Este trabalho não está concluído (LONDRES, 2014). A Tabela 2, apresentada a seguir, traz os dados reunidos e organizados até abril de 2014:

TABELA 2 - Mapeamento dos BSC da ASA -Paraíba - Resumo dos dados coletados até abril de 2014.

\begin{tabular}{|c|c|c|c|c|c|c|}
\hline REGIÃO & $\begin{array}{l}\text { № DE } \\
\text { BSCS }\end{array}$ & $\begin{array}{c}\text { № DE } \\
\text { BANCOS } \\
\text { MÃE }\end{array}$ & $\begin{array}{c}\text { № DE } \\
\text { BANCOS } \\
\text { REGIONAIS }\end{array}$ & $\begin{array}{c}\text { № TOTAL } \\
\text { DE } \\
\text { BANCOS }\end{array}$ & $\begin{array}{c}\text { № TOTAL DE } \\
\text { FAMILIAS } \\
\text { ENVOLVIDAS }\end{array}$ & $\begin{array}{c}\text { № DE } \\
\text { VARIEDADES } \\
\text { CONSERVADAS }\end{array}$ \\
\hline Alto Sertão & 29 & & & 30 & 641 & 25 \\
\hline Médio Sertão & 25 & & & 25 & 545 & 12 \\
\hline $\begin{array}{l}\text { Coletivo } \\
\text { Regional do } \\
\text { Cariri e } \\
\text { Seridó } \\
\text { Paraibano }\end{array}$ & 30 & & 01 & 31 & 440 & 30 \\
\hline $\begin{array}{l}\text { Coletivo do } \\
\text { Curimataú }\end{array}$ & 07 & & & 07 & 216 & 14 \\
\hline $\begin{array}{l}\text { Polo da } \\
\text { Borborema }\end{array}$ & 62 & 01 & 04 & 67 & 999 & 36 \\
\hline $\begin{array}{l}\text { Coletivo do } \\
\text { Folia }\end{array}$ & 01 & & & 01 & 30 & 04 \\
\hline $\begin{array}{l}\text { Casaco - } \\
\text { Coletivo Asa } \\
\text { Cariri } \\
\text { Oriental }\end{array}$ & 04 & & & 04 & 68 & 16 \\
\hline $\begin{array}{l}\text { Brejo } \\
\text { Total }\end{array}$ & $\begin{array}{c}03 \\
155\end{array}$ & 01 & 05 & $\begin{array}{c}03 \\
161\end{array}$ & $\begin{array}{c}57 \\
2996\end{array}$ & $\begin{array}{l}06 \\
36\end{array}$ \\
\hline
\end{tabular}

Fonte: LONDRES, (2014).

As ações da ASA estão pautadas, principalmente, na cultura do estoque de água, alimentos, sementes, animais e todos os elementos necessários à vida na região. Daí que as tecnologias de captação e armazenamento de água para consumo humano ao lado de casas e de escolas rurais e para produção de alimentos têm grande importância dentro desta estratégia. Além do estoque de água, o estoque de sementes também se faz necessário para que a população do Semiárido amplie ainda mais as condições práticas de conviver com a região (ASA BRASIL, 2017). 
Desta forma a conservação das sementes da paixão na Paraíba, como pode ser observado, é de fundamental importância em primeiro lugar pelo fato de perpetuar uma tradição e uma identificação dos agricultores com as sementes que os alimenta; em segundo lugar por não criar uma dependência dessas pessoas com relação aos grãos e aos preços do mercado; e por fim e não menos importante pelo fato de tais sementes serem resistentes ao solo e ao clima das regiões onde são produzidas.

\section{CONSIDERAÇ̃̃ES FINAIS}

As sementes da paixão como podemos observar mais do que um grãos ou parte da planta capaz de dar origem a outra planta, é um patrimônio das comunidades rurais do semiárido. São sementes produzidas por pequenos agricultores familiares, indígenas, quilombolas e assentados e passadas geração após geração em uma troca não só de material agrícola, mas em uma troca cultural. Essa troca cultural é pouco provável nos sistemas de produção de larga escala, uma vez que as grandes plantações ou as plantações de grãos voltadas para grandes e médios mercados não se preocupam de forma afetiva com o armazenamento dos seus produtos.

Colocando em análise o termo sustentabilidade enquanto tripé que leva em consideração o econômico, o ambientalmente justo e o socialmente justo não só para a sociedade, mas para o ecossistema, as sementes crioulas ou sementes da paixão como são conhecidas no semiárido paraibano obedecem aos critérios de sustentabilidade tanto no que diz respeito ao respeito e convivência com o ambiente quanto na preocupação em deixar um legado alimentar para as gerações futuras, pois tais sementes em muitas comunidades já perpassaram a mesa de várias linhagens no decorrer do tempo.

Enquanto que aos olhos de especialistas em desenvolvimento, as comunidades rurais familiares que guardam as sementes da paixão representam um fracasso no desenvolvimento econômico, para os defensores da ecologia agrária elas representam o sucesso em relação à conservação da diversidade; e é precisamente essa capacidade de gerar e manter recursos genéticos de cultivos diversificados que oferece possibilidades "únicas" de nicho aos agricultores familiares.

A Semente é base de alimento, de multiplicação, de crescimento, de sobrevivência, é elemento básico da agricultura como estratégia social. O maior aprendizado, sem dúvida, é a compreensão de que a preservação da cultura é importante chave para a preservação da biodiversidade.

Essa capacidade de valorização e de manter através de uma tradição a passagem de sementes de dadas variedades no decorrer do tempo, bem como o conhecimento acerca de tais grãos, faz com que as comunidades não estejam submetidas às variações do mercado, nem estejam sujeitas aos grãos produzidos artificialmente que por vezes são submetidas a agrotóxicos que tanto fazem mal ao homem quanto degradam o ambiente.

Nesse sentido pode-se asseverar a grande importância do incentivo estatal a partir de políticas públicas na valorização das sementes da paixão em decorrência não só do valor nutricional, mas também em decorrência do valor histórico, cultural e social que estas carregam. 


\section{REFERÊNCIAS}

ALMEIDA, P., CORDEIRO, Â. Semente da Paixão: estratégia comunitária de conservação de variedades locais no semiárido - Rio de Janeiro: AS-PTA, 2001.

ALMEIDA, P.; FREIRE, A. Conservando as sementes da paixão: duas histórias de vida, duas sementes para a agricultura sustentável na Paraíba. In: Sementes, patrimônio dos povos a serviço da humanidade. H.M Carvalho (org). São Paulo: Ed.Expressão popular. p. 279-302. 2003.

ASA. Semiárido. Página Inicial. Disponível em: <http://www.asabrasil.org.br>. Acesso em junho de 2017.

ARAÚJO, S. L.; MORAIS, R. C.; MORAIS, R.; NUNES, F. R.; COSTA, C.; SANTOS, M. S.. Guardiões e guardiãs da agrobiodiversidade nas regiões do Cariri, Curimataú e Seridó Paraibano. Cadernos Agroecológicos, 8(2): 1-5. 2013

ASA. Semiárido. Página Inicial. Disponível em: <http://www.asabrasil.org.br>, acesso em maio de 2017.

BEVILAQUA, G. A. P.; ANTUNES, I. F. Agricultores guardiões de sementes e o desenvolvimento in situ de cultivares crioulas. 2008. Artigo em Hypertexto. Disponível em: <http://www.infobibos.com/Artigos/2008_4/guardioes/index.htm>, acesso em abril de 2017.

BRASIL. Lei n. 9.456, de 25 de Abril de 1997. Brasília: Presidência da República do Brasil, 1997. Disponível em: http://www.planalto.gov.br/ccivil_03/leis/L9456.htm> Acesso em Maio de 2017.

BUARQUE, S. C. Construindo o desenvolvimento local sustentável: metodologia de planejamento. Editora Garamond, 2002.

CARRER H.; BARBOSA A. L.; RAMIRO D. A. Biotecnologia na agricultura. Estudos Avançados, v. 24, n. 70, São Paulo, 2010.

DIAS, E.; PORFILIO, A.; FREIRE, A. G. Semente da Paixão: Catalogo das sementes crioulas da Borborema - Esperança/PB: AS-PTA, 2016.

FUNDAÇÃO JOAQUIM NABUCO (Fundaj), Disponível em: $<$ http://www.fundaj.gov.br/index.php?option=com_content\&view=article\&id=1174\%3 Aparaiba-170-municipios-do-semi-arido\&catid=75\&ltemid=717> , acesso em maio de 2017.

IBGE - Instituto Brasileiro de Geografia e Estatística , 2017. Disponível em: <http://www.ibge.gov.br/home/>, acesso em maio de 2017.

LIMA, M. A. A. de, WERHMANN, M. E. S. de F. Convivência com o Semiárido: Quais Desafios para o Programa Garantia-Safra no Ceará? VI Encontro Nacional da ANPPAS, 2012. 
LONDRES, F. As sementes da paixão e as políticas de distribuição de sementes na Paraíba. Rio de Janeiro: AS-PTA, 2014.

MIKHAILOVA, I. Sustentabilidade: Evolução dos conceitos teóricos e os problemas da mensuração prática. Revista Economia e Desenvolvimento, n. 16, Santa Maria, RS, 2004.

MORAIS, R. C. ; ARAUJO, S. L. ; OLIVEIRA. P.N ; OLIVEIRA, F. R. N. ; SANTOS, A. S. . Sementes da Paixão cultivando vidas e saberes no Cariri, Curimataú e Seridó Paraibano. Revista Agriculturas (Impresso), v. 11, p. 19-23, 2014.

NUÑEZ, P. B. P.; MAIA. A. L. Sementes crioulas: um banco de biodiversidade. Revista Brasileira de Agroecologia, v. 1, n. 2, 2006.4p.

OLIVEIRA, L. R. de; MEDEIROS, R. M.; TERRA, P. B.; QUELHAS, O. L. G. Sustentabilidade: da evolução dos conceitos à implementação como estratégia nas organizações. Revista Produção, v. 22, n. 1, p. 70-82, Santa Catarina, 2012.

PACHECO, M. E. Agricultura familiar: sustentabilidade ambiental e igualdade de gênero. GT Gênero-Plataforma de Contrapartes Novib (Org.). Perspectiva de gênero; debates e questões para as ongs. Recife. Luci Artes Gráficas LTDA, p. 138161. 2002.

PAULINO, J. S.; GOMES, R. A. Sementes da Paixão: agroecologia e resgate da tradição. Revista de Economia e Sociologia Rural [online], v. 53, n. 3, pp.517-528 2015.

PENA, R. F. A. Agricultura no Brasil atual. Artigo em Hypertexto. Disponível em: < http://mundoeducacao.bol.uol.com.br/geografia/agricultura-no-brasil-atual.htm>, acesso em abril de 2017.

RODRIGUES, P. G.; Sustentabilidade Aplicada: possibilidade de uma organização sustentável. $\quad$ Techoje, $2012 . \quad$ Disponível em <http://www.techoje.com.br/site/techoje/categoria/impressao_artigo/1491>, acesso em maio de 2017.

SANTOS, A. S. DOS; CURADO, F. F.; SILVA, E. D. DA; PETERSEN, P. F.; LONDRES, F. Pesquisa e Política de Sementes no Semiárido Paraibano Aracaju : Embrapa Tabuleiros Costeiros, 2012. 60 p. (Documentos / Embrapa Tabuleiros Costeiros, ISSN 1678-1953; 179).

SANTOS, A. S.; SILVA, E. D.; MARINI, F. S.; SILVA, M. J. R.; FRANCISCO, P. S.; VIEIRA, T. T.; CURADO, F. F. Rede de bancos de sementes comunitários como estratégia para conservação da agrobiodiversidade no Estado da Paraíba. In: II Congresso Brasileiro de Recursos Genéticos, 2012. Anais. Belém, PA. 2012.

SILVA, E. D. da; ALMEIDA, P. Um passeio pela Festa da Semente da Paixão. Revista Agriculturas, v. 4, n 3. 2007. 
SILVEIRA, L.; PETERSEN, P. SABOURIN, E. Agricultura Familiar e Agroecologia no Semi-árido. Avanços a partir do Agreste da Paraíba - Rio de Janeiro: ASPTA, 2002.

SUASSUNA, J. SEMI-ÁRIDO: Proposta de convivência com a seca. FUNDAJ/DESAT, $\quad 2002, \quad 14 \mathrm{p}$. Disponível em $<$ http://www.fundaj.gov.br/index.php?option=com_content\&view=article\&id=659\&ltem id=376>, acesso em maio de 2017.

TRINDADE, C, C. Sementes crioulas e transgênicos, uma reflexão sobre sua relação com as comunidades tradicionais. Universidade do Estado do Amazonas. 2006.

Disponível

em:

<http://www.publicadireito.com.br/conpedi/manaus/arquivos/anais/manaus/estado_di r_povos_carina_carreira_trindade.pdf $>$, Acesso em março de 2017

ZANONI, M. e FERMENT G. (Orgs.). Transgênicos pra quem? Brasília: MDA, 2011. 